\title{
High-speed flow and fuel imaging study of available spark energy in a spray-guided direct-injection engine and implications on misfires
}

\author{
B Peterson ${ }^{1 *}$ and V Sick ${ }^{1,2}$ \\ ${ }^{1}$ Department of Mechanical Engineering, University of Michigan, Ann Arbor, Michigan, USA \\ ${ }^{2}$ Center of Smart Interfaces, Darmstadt, Germany
}

The manuscript was received on 7 April 2010 and was accepted after revision for publication on 19 July 2010.

DOI: $10.1243 / 14680874 J E R 587$

\begin{abstract}
The spark energy transferred under the highly stratified conditions during late injection in a spray-guided spark-ignition direct-injection (SG-SIDI) engine is not well characterized. The impact of high pressures, temperatures, velocities, and variations in local fuel concentration along with temporal and/or spatial variations on spark performance must be better characterized. Previous spark ignition studies have not addressed the full range of conditions that are present in SG-SIDI engines. Therefore, high-speed particle image velocimetry (PIV) experiments are conducted to characterize the spark energy dependence for a wide range of well-defined homogeneous fuel-air equivalence ratios $(\Phi=0-2.9)$ and average air velocities $(0-8 \mathrm{~m} / \mathrm{s})$ in an optical SG-SIDI engine. A moderate dependence of spark energy on equivalence ratio is shown to exist with average values of spark energy increasing by 21 per cent for the equivalence ratio range of $\Phi=0$ 2.3. Air injection into the motored engine is used to prepare well-defined flow conditions without the complications of fuel concentration gradients that are present during fuel injection. This allows the study of the effects of velocity, shear strain rate, and vorticity on spark energy. The spark energy increases with velocity at the spark plug. This observation is consistent with findings reported in the literature for low-pressure conditions. A linear increase is shown between shear strain rate and spark energy, while vorticity and spark energy are only weakly correlated. Simultaneous high-speed PIV, planar laser-induced fluorescence, and spark-discharge electrical measurements are also performed in the optical SG-SIDI engine to measure flow properties and fuel concentrations under late injection. Operating parameters are chosen to be near peak indicated mean effective pressure performance, but they occasionally provide a random misfired or partial burned cycle. Misfired cycles occur under stoichiometric-to-lean mixtures and low velocities near the spark plug. The lower spark energies observed under these conditions are in agreement with the observations made under well-controlled mixture and flow conditions reported in this study. All mixture conditions found in misfiring and partially burning cycles are within the ignitability range and fall within the general population of all, predominantly well-burning, cycles. There is no predominant impact of shear strain rate and vorticity under late injection operation on misfires and partial burns.
\end{abstract}

Keywords: flow and fuel imaging, spark energy, direct-injection engine

\section{INTRODUCTION}

The port-fuelled injection (PFI) spark-ignition engine is an intensively studied conventional gasoline engine

*Corresponding author: Department of Mechanical Engineering, University of Michigan, 2026 W. E. Lay Automotive Laboratory, 1231 Beal Avenue, Ann Arbor, MI 48109-2133, USA.

email: bpete@umich.edu configuration [1]. The PFI strategy provides a reliable yet inefficient engine load control by primarily using a throttle to adjust the amount of fuel-air mixture that enters each cylinder. The fuel-air mixtures inside the cylinder are homogeneous since the fuel and air are well mixed before entering each cylinder and are near stoichiometric as is required for after treatment of engine emissions. Ignition of the fuel-air mixture by the spark plasma is reliable since the homogeneous 
mixtures are within the flammability limits, turbulence levels are typically not strong enough to extinguish a flame kernel, and because exhaust gas recirculation (EGR) is limited in practical calibration to ensure stable combustion, especially at idle.

The conventional PFI gasoline engine has reached its limits with respect to fuel economy improvement. The introduction of the spray-guided spark-ignited direct-injection (SG-SIDI) strategy provides further fuel economy improvement in gasoline engines by operating with unthrottled air and restricting the amount of fuel to lower the load (i.e. overall lean). The limited need of the throttle plate reduces pumping losses and increases fuel economy. For stable operation at idle and low-to-moderate loads, a stratified charge is required to maintain a flammable mixture, which is achieved by injecting fuel directly into the cylinder. Here, fuel is injected late within the compression stroke directly at the spark plug, concentrating an ignitable mixture near the spark plug. The spray and spark events are highly coupled in the SG strategy with the spark event occurring during or directly after the spray event. As a result, the spark plasma is exposed to a wide variety of fuel-air mixtures, high velocity magnitudes, and velocity gradients. These conditions can lead to spark extinction, shortened spark durations, and unfavourable spark motion, which can lead to misfires [2-4]. To better understand the conditions that are required for reliable ignition, there is a need to study the spark behaviour under strong velocity fields and a wide range of fuel-air mixtures as seen under stratified operation in an SG-SIDI engine at relevant pressures and temperatures.

The fundamental physics of spark ignition and its use in internal combustion engines has been reviewed by Maly [5]. Most spark ignition studies have been conducted in enclosed chambers [6-9], constant volume combustion vessels [10-12], and SI engines $[4,13,14]$. Studies conducted in enclosed chambers and performed under moderate pressures $(<4$ bar $)$ and temperatures $(<400 \mathrm{~K})$ and do not represent the environment as seen in today's engines. Most experiments performed in SI engines focus on the ability of the spark plasma to ignite a given mixture and do not concentrate on the spark behaviour. These studies concentrate on obtaining the minimum ignition energy $[\mathbf{1 2}, \mathbf{1 5}]$, extending the lean misfire limit [16-18], and reducing cycle-to-cycle variation in SI engines [16, 19].

A few investigations have studied spark ignition under strong flow fields. Maly [20] studied spark discharges in air for velocities up to $45 \mathrm{~m} / \mathrm{s}$ to describe the effect of turbulence on minimum ignition criteria. Ballal and Lefebvre [7] obtained the minimum ignition energy for fuel-air mixtures under several velocity magnitudes $(0-15 \mathrm{~m} / \mathrm{s})$ in a closed-circuit wind tunnel. However, this study was conducted at sub-atmospheric pressures and ambient temperatures that do not match operating conditions seen in engines. Various spark plug orientations [16] and different intake port configurations [18] have been used to study spark ignition for appreciable velocities $(5-10 \mathrm{~m} / \mathrm{s})$. However, these studies do not focus on spark behaviour, but rather lean ignition and engine performance. Fansler et al. [3] and Fansler et al. [4] studied spark plasma location, spark-plasma stretching speed, and spark restrike phenomena in an SG-SIDI engine under late injection.

There have been a few studies that investigate spark behaviour under various levels of fuel concentration $[7,8,10,12,21]$. However, the majority of these studies were conducted under lean-to-stoichiometric mixtures and do not study spark behaviour in overly rich mixtures. Merer and Wallace [8] demonstrated that spark properties, such as breakdown voltage, were affected by fuel concentration. While their study only concentrates on lean and slightly rich fuel concentrations $(\Phi=0.7-1.2)$, their findings suggest the need to continue to study spark behaviour under a wider range of rich mixtures.

There are a limited number of investigations that study spark behaviour for a wide range of welldefined fuel concentrations. Ballal and Lefebvre [7] obtained minimum ignition energies for a wide range of fuel-air equivalence ratios $(\Phi=0.5-2)$ in a closedcircuit wind tunnel. However, this study was conducted under sub-atmospheric pressures and ambient temperatures, neither which mimic conditions within an engine during spark timing. Fansler et al. [14] used a wide range of fuel-air equivalence ratios $(\Phi=0-3)$ to develop a diagnostic tool for equivalence ratio measurements based on the emission intensity of the $\mathrm{CN}$ radical at $388 \mathrm{~nm}$. They applied this technique systematically to study ignition and combustion stability in a wall-guided stratified charge engine [22].

Despite previous spark ignition investigations, spark behaviour under the extreme high-velocity and multiphase fuel concentrations that are seen in SG-SIDI engines under stratified operation are not well understood. First, this investigation addresses the spark energy released under well-defined homogeneous, gas phase, fuel-air equivalence ratios and velocity values typically found under stratified charge operation in SG-SIDI engines. The spark energy is obtained 
for a wide range of homogeneous equivalence ratios ( $\Phi=0-2.9$ ) in an SG-SIDI engine under identical flow conditions. Furthermore, spark energy is measured for a wide range of average velocities at the spark gap ranging between 0 and $8 \mathrm{~m} / \mathrm{s}$ in air to eliminate any influence of equivalence ratio. Second, the data obtained for well-controlled conditions is used to interpret spark events under stratified operation. High-speed particle image velocimetry (PIV), highspeed planar laser-induced fluorescence (PLIF) imaging, and spark-discharge electrical measurements are used for this investigation. Velocity magnitude, shear strain rate magnitude, vorticity magnitude, and normalized fuel concentration are extracted in a $4 \times 4 \mathrm{~mm}$ region directly downstream of the spark plug, where the spark plasma is typically located, and correlations with spark energy are examined.

\section{EXPERIMENTAL}

\subsection{Optical engine}

Experiments were conducted on the single-cylinder optical SG-SIDI engine shown in Fig. 1(a). This engine features a twin cam, overhead valve, central injection, pentroof cylinder head, a full quartz glass cylinder, and a quartz glass Bowditch piston (Fig. 1(b)). The quartz glass windows in the cylinder head allow optical access to the fire-deck. Additionally, the piston is equipped with side windows to allow optical access within the piston bowl as the piston moves up toward top dead centre (TDC). The engine has a geometric compression ratio of $9: 1$, with an $86 \mathrm{~mm}$ bore and stroke. A schematic of the side view of the combustion chamber is shown in Fig. 1(c) to illustrate the main components within the combustion chamber. A double-pinned spark plug with a $4.6 \mathrm{k} \Omega$ internal resistance and $1.3 \mathrm{~mm}$ gap spacing is positioned slightly off the cylinder axis on one side, while an eight-hole injector sits on the opposite side of the cylinder axis. The inductive ignition system delivered an average energy of $45 \mathrm{~mJ}$ per discharge.

\subsection{Diagnostics tools}

\subsubsection{Optical setup}

The optical setup used for this investigation is shown in Fig. 2. This setup was used to simultaneously obtain PIV and PLIF measurements under stratified operation. Here, only a brief summary of the optical setup is provided to highlight its main features. More details are given in [23].

A frequency-doubled circularly polarized Nd:YLF dual cavity laser (Quantronix Darwin Duo, $527 \mathrm{~nm}$ ) was used as the light source for Mie scattering. At $4.8 \mathrm{kHz}$, each laser beam provided $5.9 \mathrm{~mJ}$ per pulse. A frequency-tripled linearly polarized Nd:YAG laser (Quantronix Hawk II, $355 \mathrm{~nm}$ ) was used for fuel fluorescence measurements. At $4.8 \mathrm{kHz}$, the laser provided $1.4 \mathrm{~mJ}$ per pulse. The $4.8 \mathrm{kHz}$ pulse rate corresponds to one pulse per engine crank angle at $800 \mathrm{rpm}$.

The green and UV laser beams were combined using a high-reflectivity $355 \mathrm{~nm}$, high-transmissivity $532 \mathrm{~nm}$ turning mirror. Laser light was sent through a set of focusing optics to form overlapping light sheets of $1 \mathrm{~mm}$ thickness. The laser sheets entered an opening in the extended crankcase and were reflected off a $45^{\circ} \mathrm{UV}$ coated mirror and aligned in the tumble plane, bisecting the tip of the fuel injector and the spark plug centre electrode.

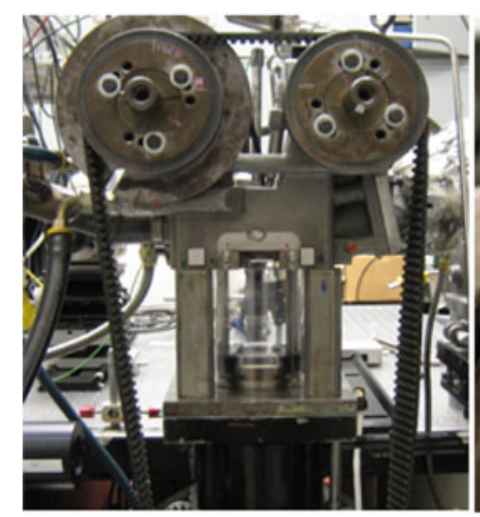

a

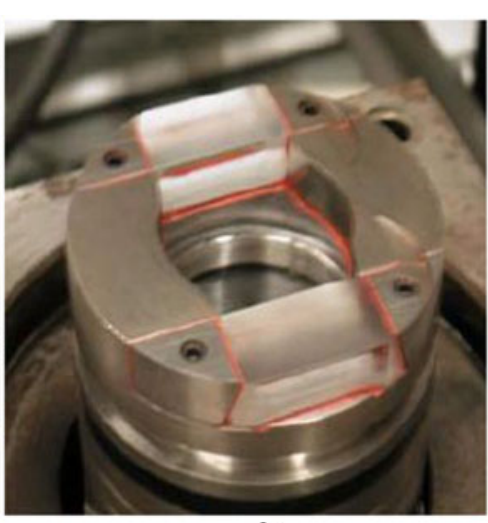

b

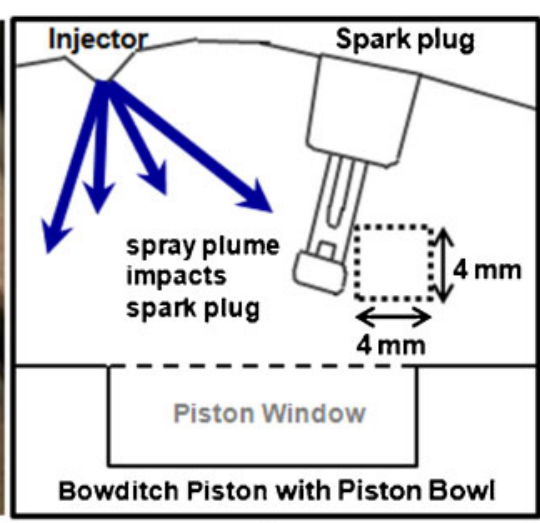

C

Fig. 1 (a) Single-cylinder optical engine, (b) Bowditch piston with quartz glass bottom and quartz glass side windows, and (c) schematic of side view of combustion chamber that highlights the main features inside the engine 


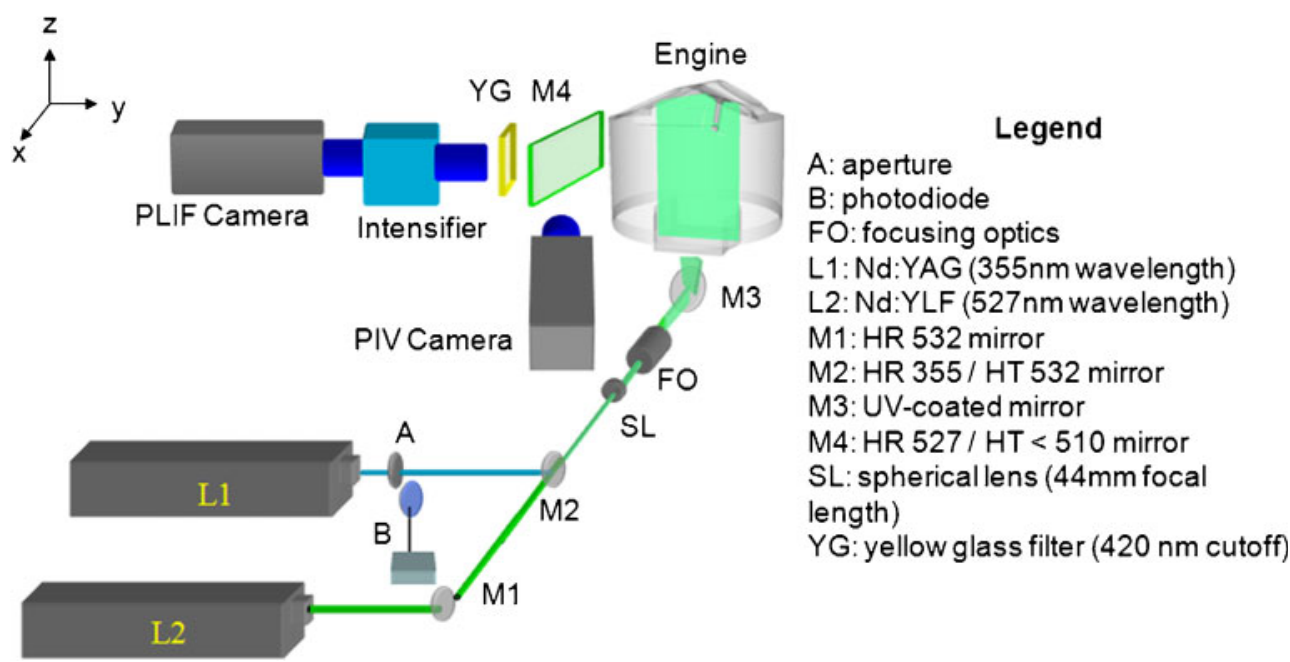

Fig. 2 Optical setup for combined PIV-PLIF experiments

A 12-bit CMOS camera (Vision Research Phantom V7.1) was used to capture Mie scattering of green laser light off of silicone oil droplets $(\sim 1 \mu \mathrm{m}$ in diameter) which were seeded into the intake air [24], while a 14bit CMOS camera (Vision Research Phantom V7.3) equipped with a lens-coupled image intensifier (LaVision HS-IRO) was used to capture fluorescence of the biacetyl fluorescence tracer in the fuel. A dielectric mirror that reflected light at $527 \mathrm{~nm}$ (Mie scattering) but transmitted below $510 \mathrm{~nm}$ (LIF signals) was placed between the engine and the PLIF camera at a $45^{\circ}$ angle. This reflected Mie scattering to the PIV camera and allowed both cameras to image perpendicular to the laser sheet in the tumble plane.

A high-speed controller (LaVision) was used in conjunction with the imaging system (LaVision DaVis) to control the timing of the cameras and lasers and their synchronization with the engine. Each laser fired once during every crank angle giving three laser pulses per crank angle degree (CAD), i.e. at a frequency of $4.8 \mathrm{kHz}$. The PIV camera operated in frame-straddling mode at $9.6 \mathrm{kHz}$, splitting each CAD into two temporally equal frames of $104 \mu \mathrm{s}$. The UV laser fired $24 \mu$ s after the second green laser pulse; the intensifier gate was opened for $300 \mathrm{~ns}$ and the PLIF camera captured the fluorescence image with an exposure time of $200 \mu$ s The time delay between the two laser pulses depended on the ability to capture the flow field inside the engine and is described in more detail for each set of experiments. For experiments solely requiring flow field images, only the PIV camera and green lasers were used, with the PIV camera positioned perpendicular to the light sheet in the tumble plane.

Vector fields and normalized fuel distribution images were determined as described in Peterson and Sick [23]. A commercial imaging software program (LaVision DaVis 7.2) was used for processing the PIV and PLIF images.

The two Mie scattering images per $\mathrm{CAD}$ were crosscorrelated with decreasing size multi-pass iterations from $128 \times 128$ pixels to a final window size of $32 \times 32$ pixels with 50 per cent overlap and two passes for each reduction in window size. The $32 \times 32$ interrogation window corresponds to a $1.7 \mathrm{~mm} \times 1.7 \mathrm{~mm}$ region for the controlled experiments and a $2.85 \mathrm{~mm} \times 2.85 \mathrm{~mm}$ region for the late injection experiments. With 50 per cent overlap, vectors are shown every one-half of the interrogation window region. A $3 \times 3$ Gaussian smoothing filter was applied to the vector field to remove noise at spatial scales near the resolution limit of PIV measurements [24].

The stratified charge fluorescence images were normalized by homogenous fuel distribution fluorescence images to portray the fuel fluorescence signal as a normalized fuel concentration (equivalence ratio). A non-linear sliding average filter of size 5 pixels was applied to the fluorescence images to smooth the fuel concentration with the region of $5 \times 5$ pixels $(0.375 \mathrm{~mm} \times 0.375 \mathrm{~mm})$. The vector field was overlaid onto the processed PLIF images and an overlay was used to clarify the position of significant features such as the spark plug and injector. The uncertainty associated with PLIF measurements using this optical setup has been estimated to be \pm 17 per cent, as characterized in detail by Smith and Sick [25].

\subsubsection{Spark measurement diagnostics}

The spark voltage was measured at the top of the double-pinned spark plug by a high-voltage probe 
(Tektronix model P6015A), while the spark current was measured using a current monitor (Pearson Model 110). Spark voltage and current signals were digitized with a high-speed digitizer (National Instruments PXI/PCI-5105) at a sampling rate of $500 \mathrm{kHz}$. The spark current signal was sent through an amplifier $(150 \times, 860 \mathrm{kHz}$ bandwidth) before digitization.

The spark energy delivered to spark gap was calculated as

$$
E_{\text {Spark }}=\int_{\text {Spark duration }}\left[\left(V_{\text {Probe }}-I \times R_{\text {Plug }}\right) \times I\right] \mathrm{d} t
$$

where $V_{\text {Probe }}$ is the voltage recorded from the highvoltage probe at the top of the spark plug, $R_{\text {Plug }}$ is the internal resistance of the spark plug, and $I$ is the spark current. The internal resistance of the spark plug, $4.6 \mathrm{k} \Omega$, was measured with an ohmmeter. The spark energy was calculated throughout the duration of the spark event. The onset of a spark began when the spark voltage and current values both became negative and the duration of the spark event lasted until the spark current value was no longer negative.

\subsection{Homogeneous fuel concentration experiments}

The spark energy was measured under a wide range of well-defined fuel-air equivalence ratios in the gas phase. Fuel was injected into the cylinder during the intake stroke (end-of-injection (EOI) at $300^{\circ}$ before top dead centre (BTDC)) allowing adequate time for fuel-air mixing to provide a homogeneous fuel-air mixture during the compression stroke and at spark timing. The fuel injector operated at a fuel pressure of 110 bar and was calibrated to provide an accurate amount of fuel at a specified injection duration. The intake air flow was controlled by a critical orifice system. An atomizer (TSI 9306) was used to seed the intake air with silicone oil droplets for PIV measurements. The atomizer air was introduced downstream of the critical orifice system and a flow meter was used to measure the additional air flow rate into the engine. Controlling and measuring the fuel and air into the cylinder gave a reliable means to calculate the equivalence ratio with an accuracy of $\Phi= \pm 0.05$.

It was desired to have a well-defined fuel-air mixture without the presence of residual combustion products within the cylinder at the time of spark. Especially for very lean and rich mixtures, high cycle variability may occur leading to variations in residual gas composition. Combustion products such as $\mathrm{CO}_{2}$ and $\mathrm{H}_{2} \mathrm{O}$ can influence spark behaviour [8] and their presence could interfere with the goal of these experiments. Therefore, the engine ran under skip-fired operation (fire one-inthree cycles) allowing two motored cycles in-between each fired cycle to scavenge residual gases and reduce the presence of combustion products within the cylinder during fired cycles.

Operating parameters for the fuel concentration experiments are shown in Table 1. Intake air was throttled to an inlet manifold absolute pressure (MAP) of $50 \mathrm{kPa}$ in order to avoid window damage from high peak cylinder pressures $(>4000 \mathrm{kPa})$ that result from combustion of stoichiometric and rich mixtures at wide-open throttle (MAP $\sim 95 \mathrm{kPa})$. To match incylinder pressures (10 bar) and temperatures $(725 \mathrm{~K})$ at spark timing for throttled operation to that of unthrottled operation (i.e. stratified operation in an SG-SIDI engine), the onset of the spark was triggered at $5^{\circ}$ BTDC. Thus, the spark timing was chosen strictly to create a similar operating environment during spark timing to that of unthrottled operation and not to optimize combustion performance.

The fuel used in this experiment was 90 per cent iso-octane, 10 per cent biacetyl by volume. This is the standard fuel mixture used in this engine for fuel fluorescence experiments. Even though LIF techniques were not applied in these experiments, it was

Table 1 Operating parameters of the experiments performed in the optical SG-SIDI engine

\begin{tabular}{|c|c|c|c|}
\hline Parameters & Fuel concentration experiments & Velocity field experiments & Stratified charge operation \\
\hline Engine speed (rpm) & 800 & 800 & 800 \\
\hline Manifold absolute pressure (kPa) & 50 & 95 & 95 \\
\hline Spark timing & $5^{\circ} \mathrm{BTDC}$ & $30^{\circ} \mathrm{BTDC}$ & $30^{\circ} \mathrm{BTDC}$ \\
\hline Spark dwell time (ms) & 3.5 & 3.5 & 3.5 \\
\hline Injection timing (physical EOI) & $300^{\circ} \mathrm{BTDC}$ & $31^{\circ} \mathrm{BTDC}$ & $32^{\circ} \mathrm{BTDC}$ \\
\hline Injection duration (ms) & $\begin{array}{l}0,1.0,1.25,1.5,1.75,2.0,2.25 \\
\quad 2.5,2.75,3.0,3.25,3.5,3.75,4.0\end{array}$ & 1.5 & 1.13 (7.2 mg fuel/cycle) \\
\hline Fuel & $90 \%$ iso-octane, $10 \%$ biacetyl & None & $90 \%$ iso-octane, $10 \%$ biacetyl \\
\hline Intake temperature $\left({ }^{\circ} \mathrm{C}\right)$ & 45 & 45 & 45 \\
\hline Oil and coolant temperature $\left({ }^{\circ} \mathrm{C}\right)$ & 90 & 90 & 90 \\
\hline Image timing & $10^{\circ} \mathrm{BTDC}-19^{\circ} \mathrm{ATDC}$ & $44^{\circ} \mathrm{BTDC}-5^{\circ} \mathrm{ATDC}$ & $44^{\circ} \mathrm{BTDC}-5^{\circ} \mathrm{ATDC}$ \\
\hline PIV time delay $(\mu s)$ & 62.5 & 20 & 20 \\
\hline
\end{tabular}


important to keep the fuel mixture consistent for comparison with the late injection measurements described later in this paper.

Experiments consisted of 100 fired cycles (300 total cycles) and each experiment was repeated twice to give a total of 300 cycles of spark events at a given fuel-air equivalence ratio, for $\Phi=0-2.9$. The PIV camera acquired two Mie scattering images per CAD from $10^{\circ}$ BTDC to $19^{\circ}$ ATDC (after top dead centre). The time delay between each laser pulse was set to $62.5 \mu$ s to adequately capture the flow field when the piston is near TDC and provided a maximum pixel shift that was within one-quater of the final interrogation window size $(32 \times 32$ pixels $)$ [26].

\subsection{Defined air flow experiments}

The spark energy was measured under a range of velocities $(0-12 \mathrm{~m} / \mathrm{s})$. This range is typically seen near the spark plug gap during the late stage of injection events in SG-SIDI engines [23]. Experiments were conducted in an unfuelled (air only) charge to isolate the effects of velocity. A high-pressure fuel injector was used to inject dry compressed air and to produce high velocities at the spark plug while maintaining the air-only charge.

As shown in Fig. 3, an eight-hole fuel injector with a $270^{\circ}$ hole pattern was used, rather than the $360^{\circ}$ hole pattern as in the fuelled experiments. This injector was used to eliminate the risk of overheating and possibly damaging the regular fuel injector used in the fuelled experiments. This injector used for air injection is referred to as the air injector throughout this investigation. One of the holes of the air injector was
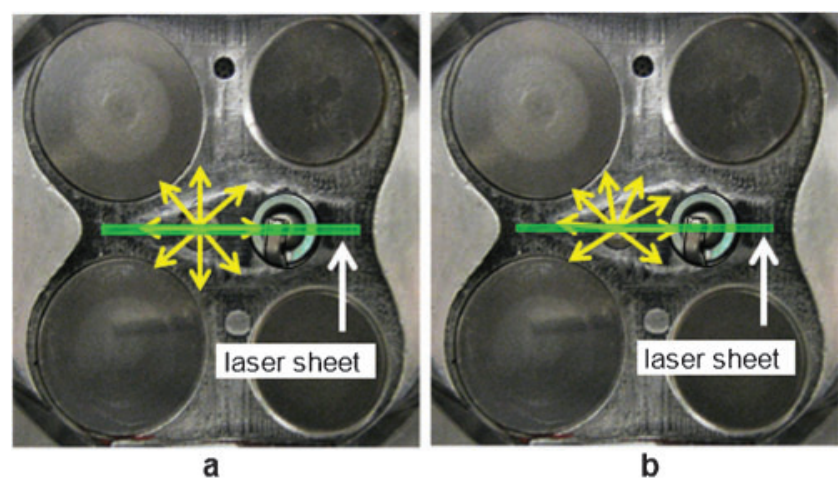

Fig. 3 (a) The fuel injector used for fuel injection experiments was an eight-hole injector with a $360^{\circ}$ hole pattern, and (b) the air injector used for the flow field experiments used an eight-hole injector with a $270^{\circ}$ hole pattern. Injector nozzles were aligned with the spark plug centre electrode to provide an impacting spray configuration aligned with the centre electrode of the spark plug to provide a jet that impacted the spark plug. This exposed the spark plug to the highest velocities from the injection event. A range of injector air pressures from zero (no injection) to 140 bar was used to vary the velocity at the spark gap.

Operating parameters for the velocity field experiments are shown in Table 1. Experiments were performed for multiple injection pressures, ranging between 0 and 140 bar, to give a wide range of velocities at the spark gap. The EOI was set to $31^{\circ}$ BTDC with an injection duration of $1.5 \mathrm{~ms}$. The onset of the spark was set to $30^{\circ}$ BTDC and was chosen to match that used under stratified charge operation.

Here, each experiment consisted of 150 consecutive cycles with injection and spark. Each experiment was repeated once to provide 300 spark events under a specific flow field from a given injection pressure. Since no fuel was injected, PIV was the only optical diagnostic technique utilized for these experiments. Mie scattering images were acquired from $44^{\circ}$ BTDC to $5^{\circ}$ ATDC for each cycle. The time delay between the two laser pulses was shortened to $20 \mu$ s in order to resolve the higher velocities from the air injection.

\subsection{Stratified charge combustion experiments}

High-speed PIV, PLIF, and spark-discharge measurements were conducted simultaneously during fired, stratified charge operation to measure flow fields and fuel concentrations near the spark plug.

The operating conditions shown in Table 1 were chosen to produce low-load idle conditions in an SGSIDI engine at $800 \mathrm{rpm}$. The engine operated unthrottled (95 kPa MAP) with $7.2 \mathrm{mg}$ fuel injected per cycle. The EOI was fixed at $32^{\circ}$ BTDC and spark timing was set to $30^{\circ}$ BTDC. The fuel used in these experiments was a mixture of 90 per cent iso-octane, 10 per cent biacetyl (percentage by volume). Best engine performance, measured in terms of the coefficient of variation (COV) of the indicated mean effective pressure (IMEP), was found within a very narrow spark timing window $\left(32^{\circ}-30^{\circ}\right.$ BTDC). At a spark timing of $31^{\circ}$ and $32^{\circ}$ BTDC, no misfires or partial burns were recorded. When spark timing was retarded to $30^{\circ} \mathrm{BTDC}$, the COV of the IMEP began to increase but overall, IMEP values for combustion cycles are similar. The spark timing of $30^{\circ}$ (with EOI of $32^{\circ}$ BTDC) provided an opportunity to study the rare occurrence of ignition instabilities with no external dilution (EGR), achieving a misfire (IMEP $<0$ ) rate of 0.6 per cent and a partial burn (mass fraction burned $<50$ per cent) rate of 0.4 per cent. 
Experiments consisted of 348 consecutive fired engine cycles and multiple experiments were performed to obtain 1392 fired cycles. Of these 1392 cycles, nine cycles were misfire cycles and five cycles were partial burn cycles. PIV and PLIF images were acquired from $44^{\circ}$ BTDC to $5^{\circ}$ ATDC. The time delay between the two green laser pulses was $20 \mu$ in order to resolve the high velocities induced by the fuel injection.

\section{RESULTS}

\subsection{Selection of measurement location}

Throughout this study the impact of fuel concentration, velocity, shear strain rate, and vorticity on available spark energy was investigated. Ideally, these quantities should be measured directly along the three-dimensional extension of the plasma channel. However, since this is experimentally not feasible, the option was explored to spatially average named quantities in an area where the spark plasma typically is found. Due to both the directed tumble flow and the impact of the fuel spray onto the spark plug electrodes, there is a strong preferred direction for the sprayinduced flow after the spray ends; the spark plasma either stays between the electrodes or gets extended along the original direction of the spray plume (Fig. 1). Based on observations of the spark plasma extension, the data were measured in a $4 \times 4 \mathrm{~mm}$ area directly downstream and adjacent to the spark plug electrodes as shown in Fig. 1. The sensitivity of the extracted spatially averaged magnitudes of velocity, shear strain rate, and vorticity was investigated by varying of the size of this extraction window. Differences were significantly lower than the cycle-to-cycle variations, confirming the validity of the selected $4 \mathrm{~mm} \times 4 \mathrm{~mm}$ area.

\subsection{Controlled experiment: homogeneous fuel- air operation}

The goal of this experiment was to measure the spark energy for a wide range of well-defined fuel-air equivalence ratios $(\Phi=0-2.9)$. Values presented in this section are ensemble averages of 300 spark events. Bars indicate one standard deviation of the 300 measurements. Baseline experiments in quiescent, ambient air show a combined repeatability of the ignition system performance and the voltage and current measurement as one standard deviation of 4 per cent for the spark energy and 3.2 per cent for spark duration.
Figure 4 shows the influence of fuel concentration on the available spark energy. A moderate trend exists between spark energy and equivalence ratio, with averaged values of spark energy showing a linear increase with equivalence ratio. The spark energy shows a 21 per cent increase in averaged values as the equivalence ratio increases from $\Phi=0$ to $\Phi=2.3$, but also exhibits an average standard deviation of 11 per cent. Beyond an equivalence ratio of 2.3, the spark energy begins to decrease and exhibits a smaller cycle-to-cycle variability. At these richer mixtures ( $\Phi=2.5-2.9$ ), an appreciable amount of soot deposits existed in the cylinder, which may influence the spark behaviour shown for these mixtures. Additional studies are necessary to further examine spark behaviour in the presence of soot deposits in the combustion chamber.

It was important to ensure that the flow field near the spark plug remained constant during these measurements. As expected, the PIV measurements showed that the different fuel injection durations during the intake stroke had no influence on the flow field near the spark plug at the time of spark. Thus, the average velocity seen during spark timing was measured as $1-2 \mathrm{~m} / \mathrm{s}$ and was consistent among all experiments. Due to the narrow range of low velocities, no correlation was found between the velocity near the spark plug and the electrical behaviour of the spark discharge for these experiments. This suggests that all trends shown here are strictly due to mixture composition near the spark plug and not velocities. However, the increase in the standard deviation of the spark

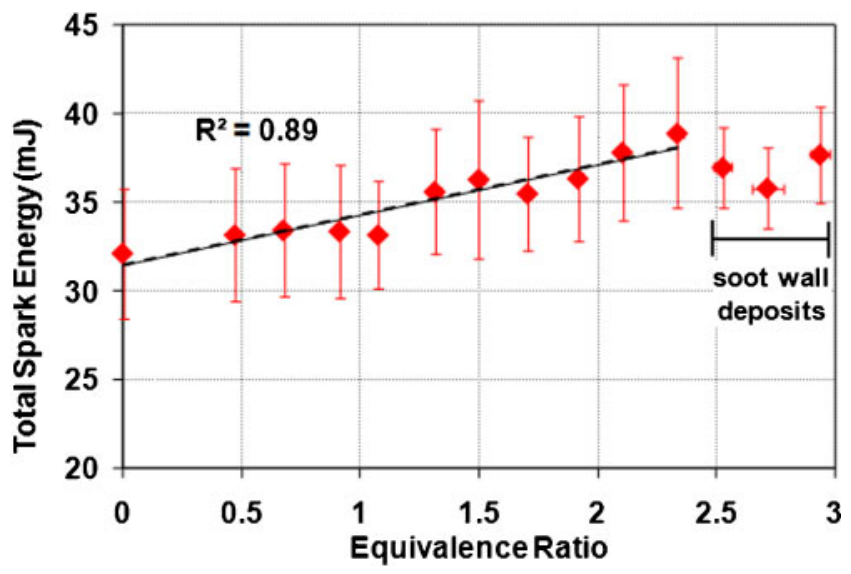

Fig. 4 A moderate trend exists between spark energy and equivalence ratio with averaged values of spark energy showing a linear increase with equivalence ratio. This relation ends beyond $\Phi \sim 2.3$, where substantial soot was present in the combustion chamber 
energy at $\Phi=0$ compared to the measurements in quiescent ambient air is attributed to velocity fluctuations in the motored engine.

\subsection{Controlled experiments: air injection}

The goal of these experiments was to measure the spark energy released under a variety of velocities seen from an air injection event. To isolate the impact of flow on spark energy, experiments were conducted in an unfuelled (air only) charge and injection velocities were produced from an air injector. Several velocity strengths were studied next to the spark plug by conducting experiments under a variety of air injection pressures $(0-140$ bar).

It is important to note that the data with air injection and without air injection (0 bar injection pressure) were collected under the same fundamental conditions and the only difference was the flow velocity. As shown in Table 1, the spark event occurs after the injection event. The spark is not exposed to a direct jet of 'fresh' air, but instead exposed to the residual flow field from the injection event. Mie scattering images reveal that the seeding is homogeneous during the spark event for air injection cases and thus would have no difference in mixture between air injection and non-injection cycles. Furthermore, seeding was shown to have no impact on the spark event (i.e. the difference in spark energy and duration with and without seeding was negligible). In-cylinder pressure was higher by 0.06 bar for maximum air injection ( $140 \mathrm{bar}$ ) at a peak pressure of $\sim 19 \mathrm{bar}$. This difference is minimal and would not drastically affect the spark energy released. Local in-cylinder temperature differences from injecting air at temperatures lower than the in-cylinder temperature can be assumed negligible as inferred from the minute pressure difference. The only other difference between the air injection and non-injection cycles is the residual velocity from the injection event. Therefore, it is argued that differences in spark energy between air injection and non-injection experiments are solely due to flow velocity.

Figure 5 shows flow field examples for two conditions. First, a sequence of velocity fields for an instantaneous cycle without air injection is shown Figs 5(a) to (c). Second, selected images from an instantaneous air injection cycle highlight flow features at the highest injection pressure (140 bar) during spark timing. The velocity field for the non-injection cycle illustrates the flow evolution that is determined by the piston motion and residual tumble from the intake flow. The edge of a vortex borders the spark

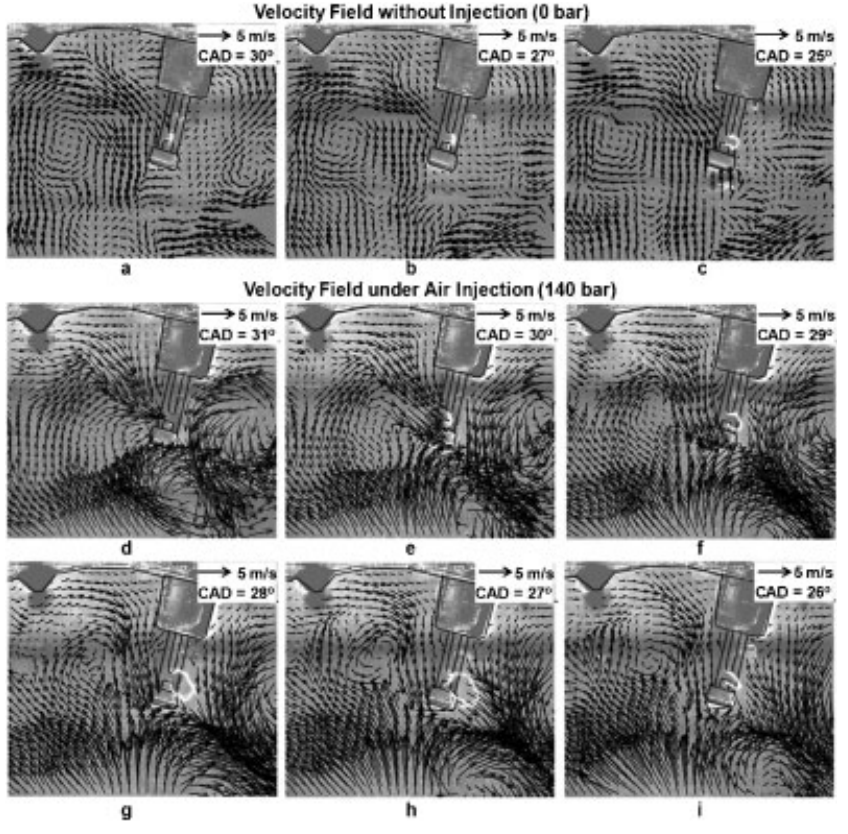

Fig. 5 Flow fields without air injection are modest providing minimal spark stretch, whereas flow fields with air injection provide higher velocities and significant spark stretch and re-strike

plug resulting in a moderate velocity magnitude upstream of the spark plug $(\sim 2-3 \mathrm{~m} / \mathrm{s})$. The spark plug obstructs the flow beyond the spark plug leaving a wake region with a relatively stagnant flow $(\sim 0.5 \mathrm{~m} / \mathrm{s})$ on the right side of the spark plug (downstream). The difference in the flow field on each side of the spark plug can lead to stretching and deformation of the spark plasma. Figure 5 shows that the spark plasma primarily remains between the spark electrodes for cycles without air injection. At $25^{\circ}$ BTDC the spark shows a mild stretch beyond the spark electrodes.

The velocity field for an air injection cycle is shown in more detail in Figs 5(d) to (i). Figure 5(d) shows the flow field one CAD prior to spark and at the end of the air injection ( $31^{\circ} \mathrm{BTDC}$ ) to illustrate the flow field during the air injection event. During the air injection, an air jet travels from the injector towards the spark plug and impacts the spark plug. Fluid in this region is dispersed and creates two recirculating regions downstream of the spark plug. As the air jet impacts the spark plug, a portion of the plume is deflected horizontally while the remaining portion of the plume passes through the spark gap and impacts the side of the piston bowl. The piston is not within the field of view for flow field images, but can be seen in Fig. 1(c). The flow deflected off the spark plug interacts with nearby boundaries (top of piston and cylinder wall) to create the circulating flow to the right of the spark plug. The flow impacting the piston bowl 
is reflected back towards the spark plug [23] creating the circulating region downstream of the spark plug and strong flow upward at the bottom of the viewing plane. During the spark event, a strong shear flow exists downstream of the spark plug, while the flow upstream the spark plug resembles that of the expired air jet. A high vertical velocity $(\sim 6 \mathrm{~m} / \mathrm{s})$ at the bottom right of the images exists throughout spark timing and is primarily due to the fluid that impacts the piston bowl and is re-directed towards the cylinder head.

For air injection cycles, the high velocity near the spark plug significantly stretches and deforms the spark plasma. In comparison to the non-injection cycle, the spark plasma in the air injection cycle shows more deformation one $\mathrm{CAD}$ after the onset of spark $\left(29^{\circ}\right.$ BTDC) than during the entire spark duration in the non-injection cycle. At $28^{\circ}$ BTDC the spark channel continues to lengthen and is shown to stretch well beyond the spark gap. The image at $27^{\circ}$ BTDC captures a re-strike event and shows two distinct plasma channels - one channel is well beyond the spark gap while another exists directly between the spark electrodes. Here, the spark discharge length reaches a limit where the plasma channel stretches well beyond the spark gap and the spark discharge cannot sustain enough new electrons and ions along the lengthening plasma channel. The elongated plasma channel ceases to exist, but a sufficient number of electrons and ions remain available at the cathode before the available electrical energy in the secondary coil is completely dissipated [5]. At this time, a new breakdown event occurs with a new plasma channel shown directly between the electrodes. Once the new plasma channel is established, the flow is still strong enough to stretch and deform the new plasma channel before the end of the spark event.

The spark voltage and current for the non-injection and air injection cycle in Fig. 5 are shown in Fig. 6. The breakdown phase of the spark discharge occurs in the order of nanoseconds and is not resolved. After the peak voltage value, the voltage drops to a level in the order of $200 \mathrm{~V}$, indicating the discharge has transitioned to either the arc or glow discharge phase [10]. As demonstrated by Lee et al. [9] at the 12 bar pressure attained here, a transition from the arc to glow phase cannot always be resolved.

For the non-injection cycle, the glow voltage primarily remains below $1000 \mathrm{~V}$ and exhibits fewer changes in voltage magnitude in comparison to the air injection cycle. This is indicative of the plasma channel undergoing minimal stretch and deformation during the spark event. The spark voltage trace for the air injection cycle shows a continual voltage increase

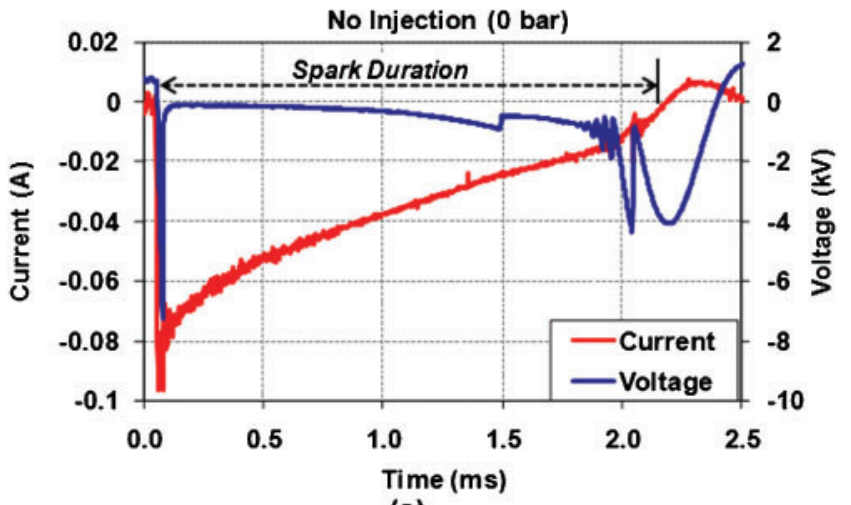

(a)

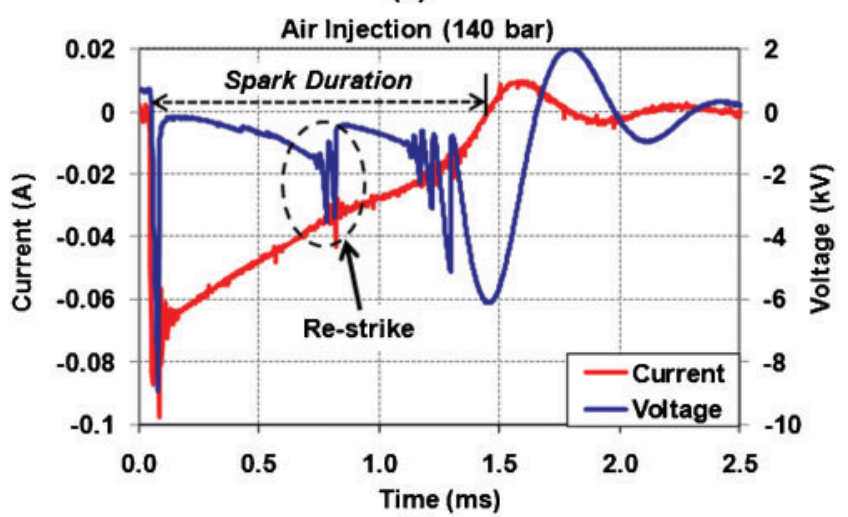

(b)

Fig. 6 Spark voltage and current traces for the noninjection and air injection cycles shown in Fig. 5. The higher voltages during the arc and glow phase for the air injection cycle indicates the lengthening of the spark channel. The breakdown event associated with re-strike shown at $27^{\circ}$ BTDC in Fig. 5(h) is indicated by the sharp increase in voltage magnitude at $0.7 \mathrm{~ms}$ in Fig 6(b)

during the arc and glow phase and is associated with the lengthening of the plasma channel. The voltage increases to a value in which the available coil voltage can no longer sustain the plasma channel, resulting in the re-strike shown at $27^{\circ}$ BTDC in Fig. 6. This restrike is associated with a new breakdown event and is indicated by a sharp increase in voltage magnitude.

The flow field was analysed in the $4 \mathrm{~mm} \times 4 \mathrm{~mm}$ region downstream of the spark plug, as shown in Fig. 1(c), and is presumed representative of the conditions surrounding the spark plasma, especially in the region where the plasma extends. Spatial averages of velocity magnitude $(\overline{|V|})$, shear strain rate magnitude

$$
\sigma=\left(\overline{\left|\frac{1}{2}\left(\frac{\partial u}{\partial y}+\frac{\partial v}{\partial x}\right)\right|}\right)
$$

and vorticity magnitude 


$$
\omega=\left(\overline{\left(\frac{\partial u}{\partial y}-\frac{\partial v}{\partial x}\right) \mid}\right)
$$

were all extracted from this region. Results presented in this section depict the ensemble-spatial average $(\langle\bar{\cdots}\rangle)$ over 300 cycles. Bars shown for data at 110 bar injection pressure indicate one standard deviation of the 300 measurements to demonstrate cyclic variability.

Figure 7(a) shows the crank-angle-resolved velocity magnitude downstream of the spark plug for each air injection pressure. The maximum velocity during spark timing occurs at the onset of the spark $\left(30^{\circ}\right.$ BTDC) right after the end of the injection. Velocities decay throughout the spark event and throughout the remainder of the compression stroke when velocities approach those seen under no injection. The rate of decay increases as the injection pressure increases. Similar velocities are seen for injection pressures of 140,110 , and 80 bar despite the differences in injection pressure. A likely explanation is that the air jet impacts the spark plug and velocities are significantly altered, possibly limiting the air velocity downstream of the spark plug.

Figure 7(b) shows the crank-angle-resolved shear strain rate downstream of the spark plug for each air injection pressure. Peak shear strain rates increase monotonically with injection pressure. During the spark discharge, shear strain rates decrease at a similar rate for all injection pressures and are significantly greater than the shear strain rates for non-injection operation. Values of shear strain rate from the injection event continue to decay throughout the remainder of the compression stroke and approach the values seen for no injection.

Figure 7(c) shows the crank-angle-resolved vorticity downstream of the spark plug for each air injection pressure. In contrast to velocity magnitude and shear strain rate, vorticity does not vary monotonically with injection pressure in the investigated area. Furthermore, at the onset of the spark the vorticity is higher for lower injection pressures and decreases as injection pressure increases. This trend along with those seen for shear strain rate and velocity indicates that the flow after the injection event is stronger with greater fluid deformation at the higher injection pressures, but shows greater fluid rotation at the measurement location for lower injection pressures. The vorticity is largest during the injection event and rapidly decreases at the conclusion of the injection event.

At the time of spark, averaged values of velocity magnitude $(8 \mathrm{~m} / \mathrm{s})$, shear strain rate $\left(1000 \mathrm{~s}^{-1}\right)$, and vorticity $\left(1200 \mathrm{~s}^{-1}\right)$ under the highest air injection

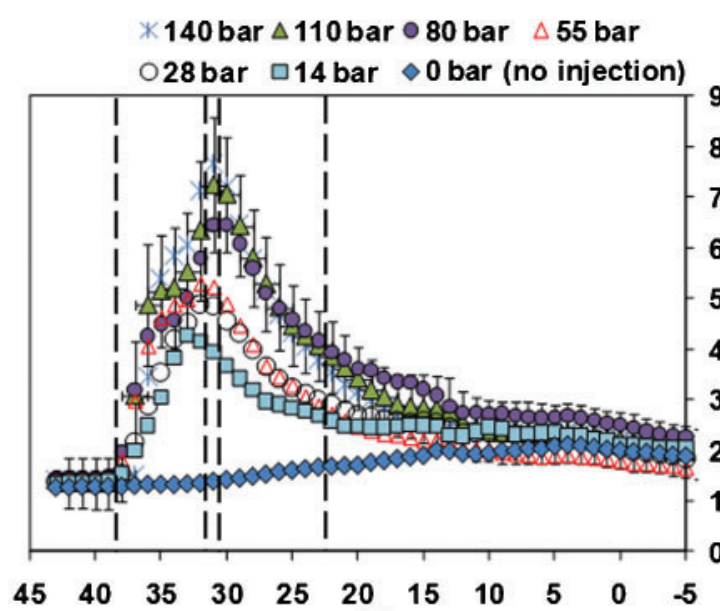

(a)

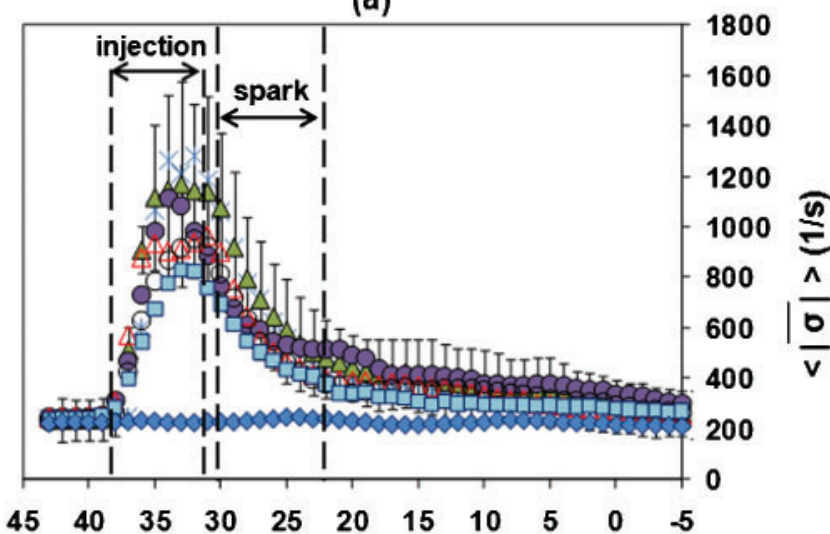

(b)

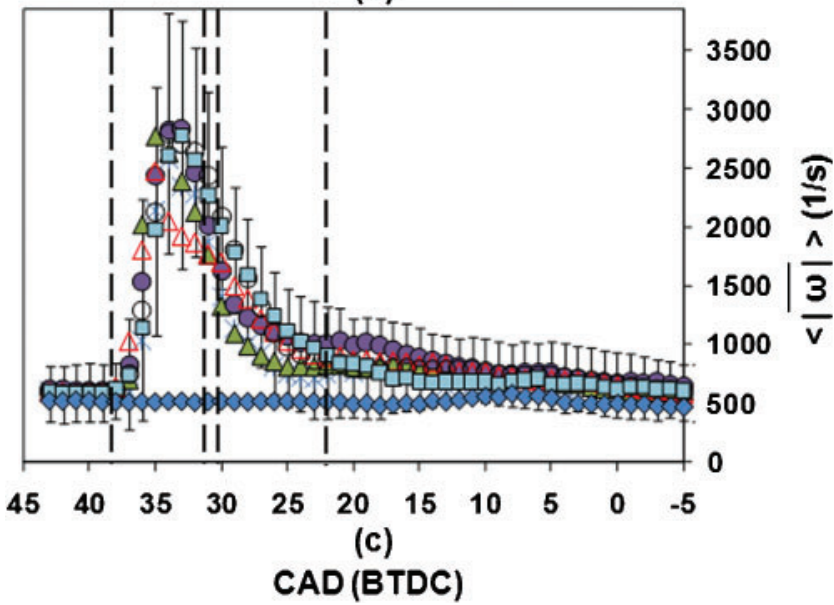

Fig. 7 (a) Ensemble-spatial average of velocity magnitude, (b) shear strain rate magnitude, and (c) vorticity magnitude during the air injection and spark event for various air injection pressures. Bars indicate one standard deviation of the 300 measurements at 110 bar to demonstrate the cycle-to-cycle variability

pressures (140 and $110 \mathrm{bar}$ ) are similar to averaged values seen under stratified operation in an SG-SIDI engine [23]. Thus, similar flow conditions have been achieved with the air injection but any complications 
due to multi-phase flow or high stratification have been avoided for the analysis of spark behaviour as a function of local velocity.

Relationships between flow properties and spark energy released to the fuel-air mixture are of high interest to build predictive models for internal combustion engine simulations. Therefore, the spark energy was correlated with velocity magnitude, shear strain rate, and vorticity measured in the $4 \mathrm{~mm} \times 4 \mathrm{~mm}$ region downstream of the spark plug. Integrated quantities for the duration of the spark discharge as well as values at the onset of the spark were examined. The onset of the spark was chosen to correlate timespecific quantities to compare results to cases of combustion in which flow field quantities beyond the onset of the spark are biased due to disappearing PIV seeding and combustion luminosity in the $4 \mathrm{~mm} \times$ $4 \mathrm{~mm}$ region.

This discussion presents both cycle-resolved quantities of the entire data set for all air injection pressures and ensemble averages computed for the 300 cycles recorded for each air injection pressure. Averaged flow field quantities throughout the entire spark event are the ensemble-temporal-spatial average represented as $\{\langle\bar{\cdots}\rangle\}$, while quantities at the onset of spark are ensemble-spatial averages and represented as $\langle\bar{\cdots}\rangle$.

Figure 8 shows the influence of velocity magnitude on spark energy. The cycle-resolved data exhibits large scatter but a positive correlation exists for a linear relationship between total spark energy and averaged velocity seen during the spark event. This is more evident when the data are ensemble averaged for each air injection pressure. As the velocity near the spark plug increases, the energy delivered to the spark plasma increases. This is primarily due to the stretching of the spark plasma (see Fig. 5) that increases the voltage between the electrodes $[\mathbf{1 1}, \mathbf{1 3}, \mathbf{1 8}]$. In addition, with higher velocities near the spark plug, re-strikes are more common which further increase the spark energy due to additional breakdown events. A linear relationship is also found for averaged quantities at the onset of the spark, but shows a weaker correlation. The weaker correlation is not too surprising since the spark plasma has not had sufficient time to stretch and is primarily located between the spark electrodes as opposed to the $4 \mathrm{~mm} \times 4 \mathrm{~mm}$ region. Time-specific data during the second and third CAD after the onset of the spark have higher correlation coefficients (not shown), most likely due to the fact that the spark plasma is within the $4 \mathrm{~mm} \times 4 \mathrm{~mm}$ region at this time. However, as previously stated this work focuses on the first CAD after onset of the spark

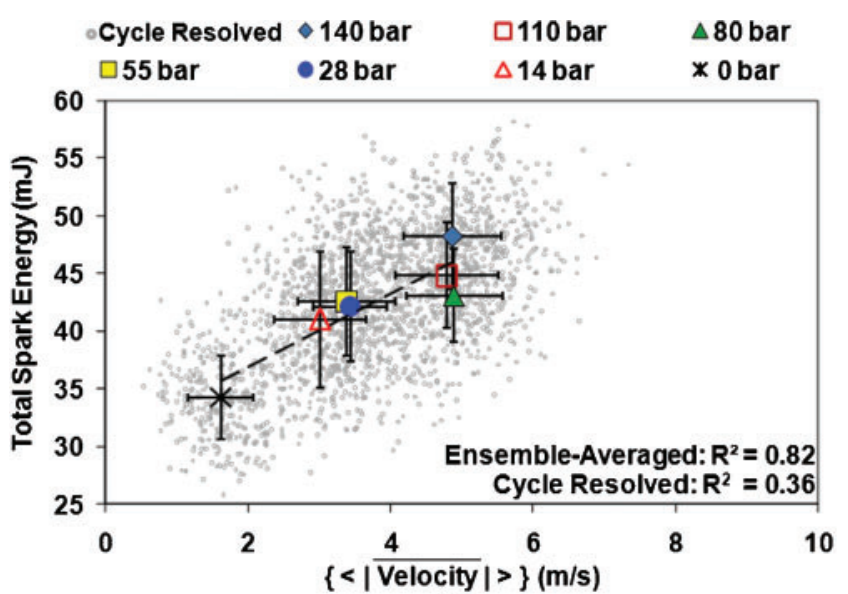

(a)

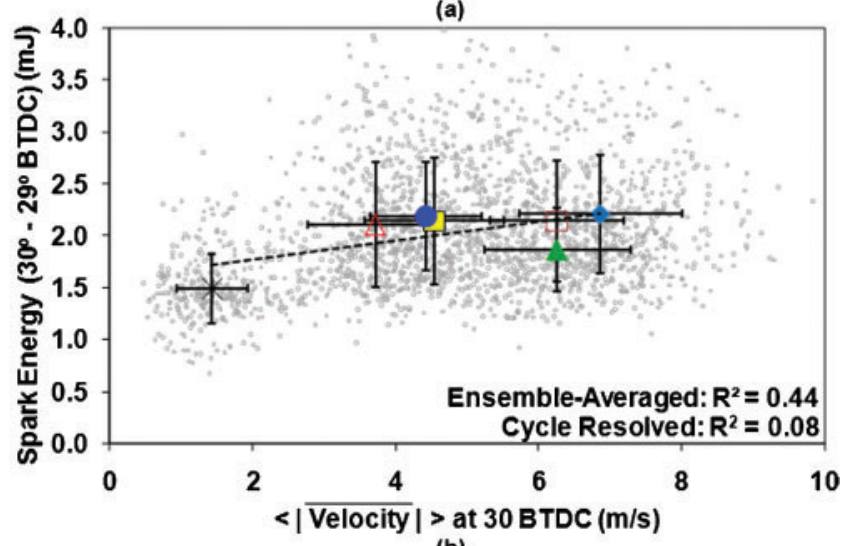

(b)

Fig. 8 A linear relationship exists between spark energy and velocity during the entire spark duration (a) and at the onset of spark (b). The spread in cycleresolved data yields lower correlations. Spark energy at the first spark $\mathrm{CAD}$ excludes the breakdown. Bars indicate one standard deviation of the 300 measurements. Cycle-resolved data are presented for all injection pressures

to be compatible with measurement restrictions under fired conditions.

Cycle-resolved data (for all injection pressures) overlaid with the injection-pressure-specific ensembleaveraged data show the cycle-to-cycle variability in the flow and shows a lower correlation. The lower correlation for the cycle-resolved data arguably reflects that the recorded velocities are not directly measured along the spark plasma channel. On average the spark plasma lies in the $4 \mathrm{~mm} \times 4 \mathrm{~mm}$ extraction region, but velocities vary across this region and the plasma channel might move out of plane since the light sheets are only $1 \mathrm{~mm}$ thick. Thus, the expected linear relationship between spark energy and velocity $[5-7,13$, 20] is observed, albeit with low correlation coefficients even close to zero for measurements during the first spark CAD. 
The total spark energy is also closely correlated with averaged shear strain rate as shown in Fig. 9. The spark energy released between the electrodes increases linearly with increasing strain rates. It is likely that the fluid deformation within the region downstream of the spark plug is similar to deformation of the actual plasma channel. This is consistent with the view that the spark plasma is transported passively by the local fluid motion [11]. The spark energy increases with plasma deformation and is consequently strongly correlated with the nearby fluid deformation. The temporal-spatial averaged shear strain rate and the strain rate at $30^{\circ}$ BTDC both correlate well with total spark energy and spark energy seen throughout the first spark CAD. Similar to cycle-resolved velocity measurements, cycle-resolved data between spark energy
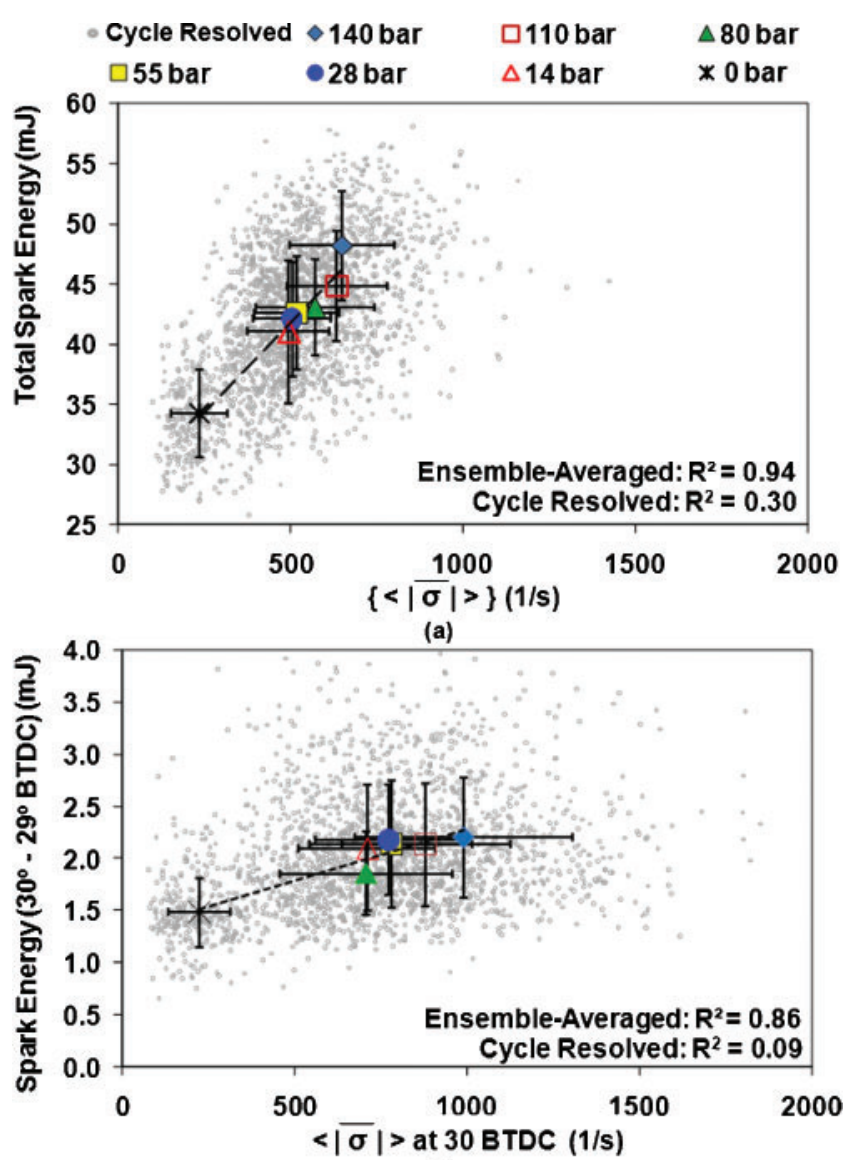

(b)

Fig. 9 A linear relationship exists between spark energy and shear strain rate magnitude during the entire spark duration (a) and the onset of spark (b). Cycle-resolved data have a large spread yielding lower correlations. Spark energy at the first spark CAD excludes the breakdown. Bars indicate one standard deviation of the 300 measurements. Cycle-resolved data are presented for all injection pressures and shear strain rate exhibit a lower correlation compared to ensemble-averaged quantities. This lower correlation again indicates that the $4 \mathrm{~mm} \times 4 \mathrm{~mm}$ region does not always contain the spark plasma channel.

The impact of vorticity near the spark plug on available spark energy is shown in Fig. 10. The total spark energy does not show an apparent, simple relationship with averaged vorticity in contrast to averaged velocity and shear strain rate. From the cycle-resolved data it is indicated that increasing vorticity does lead to an increase in spark energy but the spread in the data is very large and hence the correlation is weak. The analysis of the impact of vorticity on spark plasma stretching and in turn on spark energy will require further assessment.
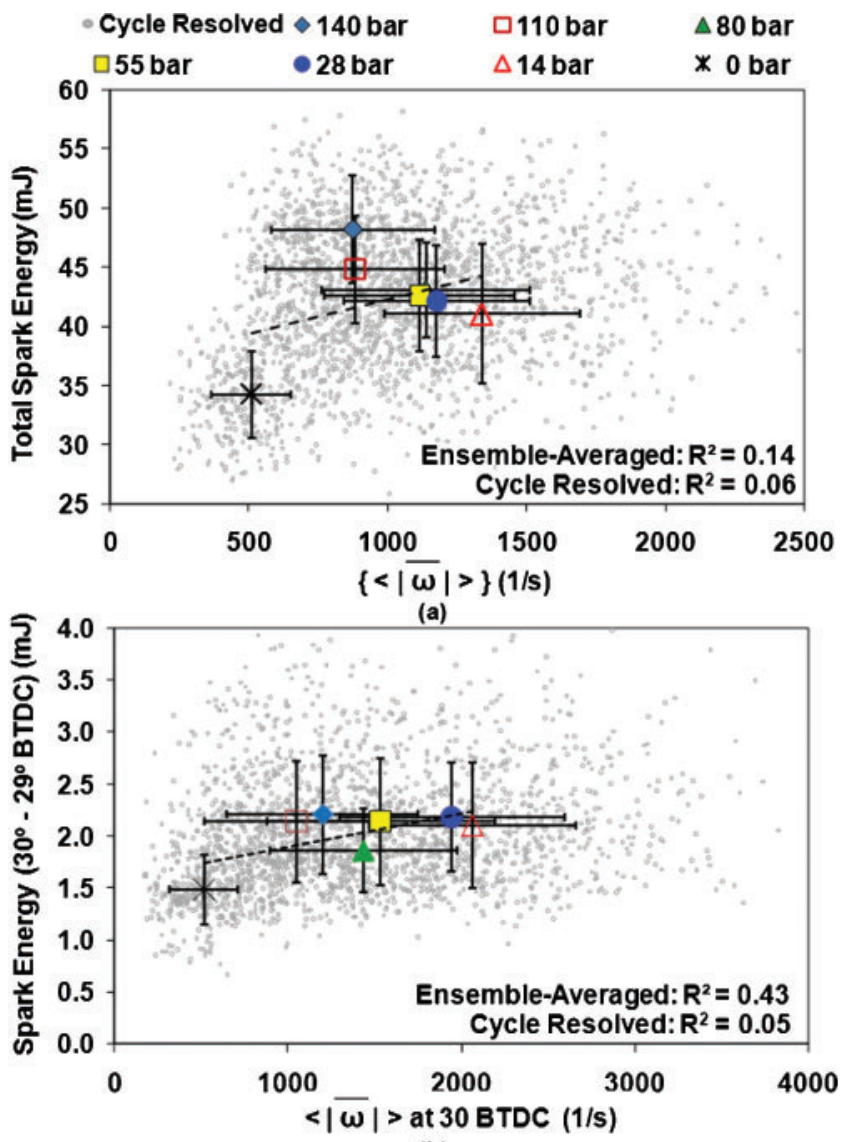

(b)

Fig. 10 (a) A linear relationship does not exist between total spark energy and averaged vorticity magnitude during the spark event, and (b) a weak positive linear relationship is shown between spark energy and vorticity magnitude at the onset of spark. Spark energy at the first spark CAD excludes the breakdown. Bars indicate one standard deviation of the 300 measurements. Cycle-resolved data are presented for all injection pressures 


\subsection{Spark energy transfer under stratified operation}

The engine was operated with late fuel injection to quantify the spark energy released under stratified low load, idle conditions. Flow field and fuel concentration near the spark plug as well as spark voltage and current measurements were used to evaluate the conditions for firing, partial burning, and misfiring cycles.

Figure 11 shows the flow field and fuel concentration of an individual cycle to demonstrate the conditions that exist within the $4 \mathrm{~mm} \times 4 \mathrm{~mm}$ region downstream of the spark plug during the spark event. Images show the flow field and fuel concentration at the EOI $\left(32^{\circ}\right.$ BTDC), at the onset of the spark $\left(30^{\circ}\right.$ BTDC), and shortly after the onset of the spark when a flame kernel exists ( $27^{\circ}$ BTDC). The dotted line at the bottom of each image indicates the position of the bottom of the piston bowl. Rich conditions exist near the spark plug at the EOI and quickly lean out to nearstoichiometric mixtures at the time of spark. A flame kernel is often present within 1-2 CAD after the onset of the spark and continues to grow by finding a mixture suitable for subsequent combustion. The short time interval between the onset of the spark and presence of the flame kernel limits the ability to capture accurate flow field and fuel fluorescence information beyond the time of spark onset. PIV seed droplets are burned and the LIF signal overlaps with combustion luminosity. Therefore, reliable velocity and fuel concentration data extracted from the $4 \mathrm{~mm} \times 4 \mathrm{~mm}$ region downstream of the spark plug are limited to times just until the first crank angle after the onset of spark.

The spark energy for the first spark CAD was correlated with spatially averaged quantities of equivalence ratio, velocity magnitude, shear strain rate magnitude, and vorticity magnitude measured in the
$4 \mathrm{~mm} \times 4 \mathrm{~mm}$ region (shown in Fig. 1) at the onset of the spark $\left(30^{\circ}\right.$ BTDC). Cycle-resolved data were used in the anticipation of finding correlations between spark energy, fuel-air equivalence ratios, and flow properties for misfired and partial burn cycles in relation to successful combustion cycles.

As previously mentioned, the breakdown event was not resolved in the spark measurements; therefore the spark energy presented here begins at the onset of the arc phase once the voltage stabilizes after the initial voltage peak. Measurements shown are for 1392 combustion cycles and highlight the misfired and partial burn cycles. Out of the 1392 cycles, nine cycles were misfire cycles (IMEP $<0$ ) and five cycles were partial burns (mass fraction burned $<50$ per cent).

Figure 12 shows spark energy, equivalence ratio, and velocity measurements for the 1392 combustion cycles. Measurements of equivalence ratio are scattered around stoichiometric mixtures with data points spanning the ignitability limits [1]. Measurements of spark energy and fuel-air equivalence ratio do not show a significant correlation, while measurements of spark energy and velocity show a positive weak relationship. However, the data does clearly show that misfired and partial burn cycles occurred for near-stoichiometric-to-lean mixtures and low velocities at the spark plug. It is also shown that these misfires and partial burns had lower spark energies during the first CAD. These results are in agreement with the results shown from the controlled experiments - available spark energy is less for leaner mixtures and lower velocities.

It was shown recently [27] that for the conditions discussed above a flame kernel is always formed, regardless of mixture and flow conditions. However, in some cases the combination of the low velocities, lean mixtures, and low spark energies does not provide

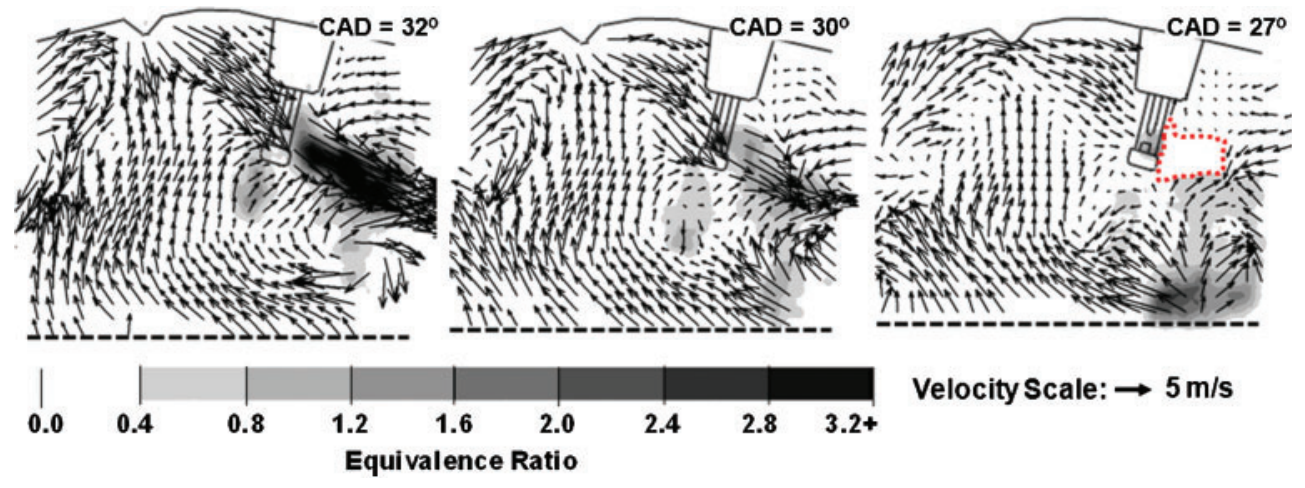

Fig. 11 Simultaneously acquired PIV and PLIF images of an instantaneous cycle show the flow field and fuel concentration at EOI ( $32^{\circ}$ BTDC), spark timing ( $30^{\circ}$ BTDC), and when a flame kernel is established $\left(27^{\circ}\right.$ BTDC) 

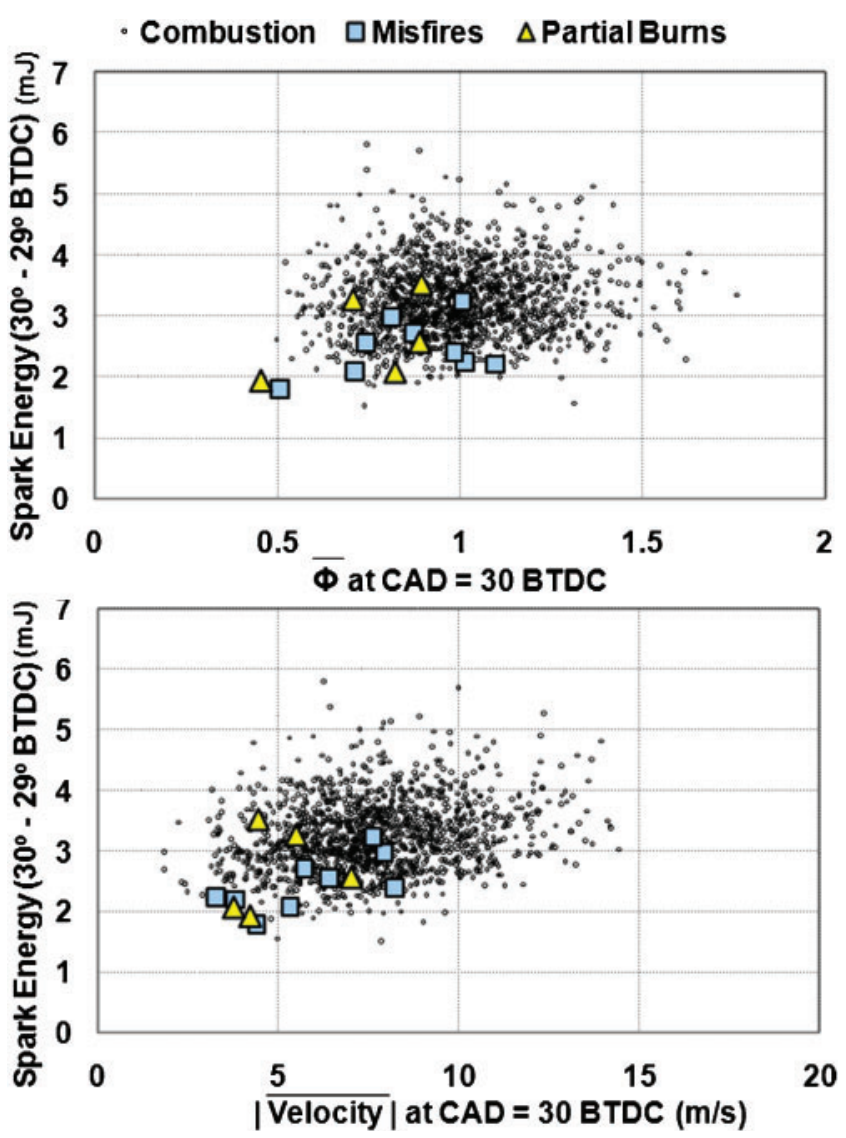

Fig. 12 Misfired and partial burn cycles occurred under near-stoichiometric-to-lean mixtures and low velocities

favourable conditions for developing a flame kernel into a self-sustained flame. Under low velocities, the spark plasma channel undergoes less stretch, which can limit its exposure to ignitable mixtures. As represented in Fig. 11, the tail end of the flammable mixture is located near the edge of the spark plug at the spark timing and is quickly moving away. This is consistent for all engine cycles. Mixtures near the spark plug become leaner with time and this can lead to a slowly developing flame kernel (flame speeds are lower for leaner mixtures) that cannot catch up to the flammable mixture for subsequent combustion. Furthermore, with less spark energy available to the mixture, flame kernel development is prolonged [5], creating yet another situation where the flame kernel lags behind the flammable mixture.

Figure 13 shows spark energy, shear strain rate magnitude, and vorticity magnitude for the 1392 fired cycles highlighting the misfired and partial burn cycles. Similar to equivalence ratio, cycle-resolved measurements between spark energy, shear strain rate, and vorticity do not show any significant correlation $\left(R^{2}<0.05\right.$ but positive). Values of shear strain rate primarily lie

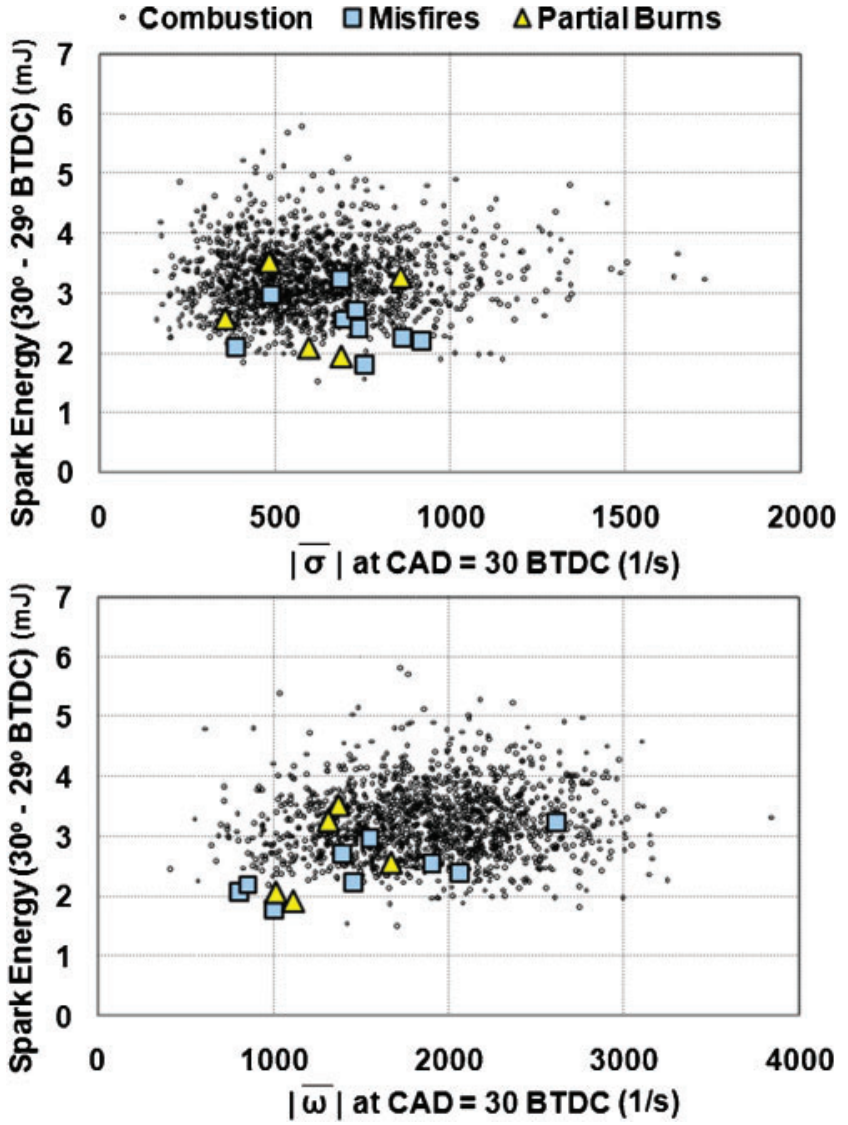

Fig. 13 Misfires and partial burns are not sensitive to initial values of shear strain rate (top) and vorticity (bottom) near the spark plug

below $1000 \mathrm{~s}^{-1}$ with misfired and partial burn cycles spanning this range. Vorticity values for misfired and partial burn cycles primarily fall within the lower vorticity values measured, with the exception of one misfire at a vorticity of $\omega=2600 \mathrm{~s}^{-1}$. This demonstrates that initial shear strain rates and vorticities are not indicators of deficient cycles.

Overall, the range of values for velocity, shear strain rate, and vorticity in the air injection experiments are similar to values revealed under stratified operation. However, despite similar or even higher injection pressures for air injection cycles, the velocity ranges under stratified operation with fuel injection $(2-15 \mathrm{~m} / \mathrm{s})$ are larger than what was seen under air injection (3-9 m/s). This is expected, given that the jet penetration is a function of the density ratio between injected fluid and the in-cylinder air. This ratio is lower for the air injection thus the penetration towards the spark plug is reduced and lower velocities are expected behind the spark plug. The inclusion of non-injection cycles provides spark energy characterization in the lower velocity regime $(1-2 \mathrm{~m} / \mathrm{s})$. 


\section{CONCLUSIONS}

Spark ignition under highly stratified conditions in SG direct-injection engines is difficult to predict numerically since the underlying specifics for energy transfer from the spark plasma to the fuel-air mixture are not well characterized for conditions that are present in such engines. The impact of high pressures, temperatures, velocities, and variations in local fuel concentration along with temporal and/or spatial variations on spark performance must be known. Even though high-speed imaging techniques have already allowed unique insights into the transient nature of in-cylinder processes there is still a lack of fundamental understanding of ignition properties under stratified, highpressure conditions. Past work has primarily addressed minimum ignition energies and their dependence on a range of variables. In many cases these studies were conducted under non-engine-like conditions, mostly low pressures and homogeneous mixture conditions.

High-speed PIV experiments were conducted to characterize the spark energy dependence on equivalence ratio as well as flow velocity, shear strain rate, and vorticity at the spark plasma. Data were extracted from the images in a $4 \times 4 \mathrm{~mm}^{2}$ region just downstream of the spark plug. On average, this is the region where the spark plasma extends. For fixed flow conditions the amount of energy transferred to the fuel-air mixture of equivalence ratios ranging between 0 and 2.9 was determined for direct-injection engine pressures and temperatures. A moderate linear dependence of spark energy on equivalence ratio was noted with averaged values increasing by 21 per cent in the equivalence ratio range $\Phi=0-2.3$. It was also observed that spark energy is affected substantially by the presence of soot in the combustion chamber, but additional experiments are needed for further validation and characterization.

The impact of velocity, shear strain rate, and vorticity on the amount of energy transferred is much stronger under the applicable range of flow fields in an SG-SIDI engine. Variations in excess of 40 per cent were observed over the investigated range. Experiments were conducted in a motored engine to provide pressure and temperature conditions that are commensurate with spark ignition direct injection. Fuel was not injected to eliminate the effects of fuel stratification on spark energy. Instead, operating a fuel injector as an air injector induced flow conditions at the spark plug that are typical for SG engine operation.

The air jet velocity was adjusted by varying the air injection pressure. Measured flow data were then analysed in two ways. First, averages and their cycle- to-cycle fluctuations were correlated with spark energy data. Second, cycle-resolved data were correlated with individual spark energy measurements for the entire data set from all injection pressures. In contrast to the spark energy dependence on equivalence ratio the relationships obtained for flow properties should be interpreted as trends only, given that the flow measurements were performed such that only in a statistical sense the plasma was contained in the measurement volume. The amount of transferred spark energy increased linearly with velocity at the spark plug; this is in agreement with previous findings reported in the literature for low-pressure conditions. In addition, it was observed that increasing the shear strain rate also leads to a linear increase in spark energy. A linear increase of spark energy with increasing vorticity was only confirmed with very low correlation. The spread of individual data is much larger than what was observed for velocity and shear strain rate influence on spark energy. Cycle-resolved data show significantly lower correlations and this arguably reflects that the recorded velocities are not directly measured along the spark plasma channel. On average the spark plasma lies in the $4 \mathrm{~mm} \times 4 \mathrm{~mm}$ extraction region, but velocities vary across this region and the plasma channel might move out of plane since the light sheets are only $1 \mathrm{~mm}$ thick.

Simultaneous high-speed PIV and PLIF measurements were performed in the optical SG-SIDI engine under late injection, stratified operation. Operating conditions were chosen to be near peak IMEP to provide near-optimum engine performance yet produce misfire and partial burn cycles on occasion. Images show the velocities and fuel concentrations around the spark plug as well as their gradients during the time of spark. As a result, it can be concluded that modelling approaches to the determination of the spark energy must include spatially and temporally resolved information on local equivalence ratio and flow conditions since both vary and have an impact on the amount of available spark energy as shown in this work. Images also show the short time duration between the onset of spark and the presence of a flame kernel. The onset of combustion limits the application of liquid droplet PIV and biacetyl PLIF in this application. Therefore, the analysis of spark energy transfer and its relation to misfires and partial burns focused on the assessment and correlations of mixture and flow conditions at the beginning of the spark event.

Spark energy was correlated with equivalence ratio, velocity magnitude, shear strain rate magnitude, and vorticity magnitude for 1392 combustion 
cycles. Misfired and partial burn cycles occurred for conditions where near-stoichiometric-to-lean mixtures and low velocities were observed downstream of the spark plug to where the spark plasma was convected. A lower energy transfer under these lean mixtures and low velocities shortly after spark breakdown are in agreement with the observations made under well-controlled mixture and flow conditions that are reported in this study. It is important to note that mixture conditions found in misfiring and partially burning cycles are within the ignitability range and fall within the general population of all, predominantly well-burning, cycles. There was no predominant grouping of the values for shear strain rate and vorticity at the onset of spark for the misfired and partial burned cycles compared to successful cycles.

\section{ACKNOWLEDGEMENTS}

This work was supported by the General Motors Company through the General Motors-University of Michigan Collaborative Research Laboratory on Engine Systems Research. The authors are grateful to Arun Solomon, Michael C. Drake, and Todd D. Fansler at General Motors Company. Support from David L. Reuss and Louise Lu at the University of Michigan is acknowledged. This paper was presented at the Ninth International Symposium on Combustion Diagnostics, Baden-Baden, Germany, 8-9 June 2010.

(C) Authors 2010

\section{REFERENCES}

1 Heywood, J. B. Internal combustion engine fundamentals, 1988 (McGraw-Hill, New York).

2 Smith, J. D. and Sick, V. A multi-variable highspeed imaging study of ignition instabilities in a spray-guided direct-injected spark-ignition engine. SAE paper 2006-01-1264, 2006.

3 Fansler, T. D., Drake, M. C., Düwel, I., and Zimmermann, F. P. Fuel-spray and spark plug interactions in a spray-guided direct-injection gasoline engine. In Proceedings of the Seventh International Symposium on Internal combustion diagnostics, Baden Baden, 18-19 May 2006, (AVL Deutschland, Mainz-Kastel) pp. 81-97.

4 Fansler, T. D., Drake, M. C., and Böhm, B. Highspeed Mie-scattering diagnostics for spray-guided gasoline engine development. In Proceedings of the Eighth International Symposium on Internal combustion diagnostics, Baden Baden, 10-11 June 2008, (AVL Deutschland, Mainz-Kastel) pp. 413-425.
5 Maly, R. Spark ignition: its physics and effect on the internal combustion engine. In Fuel economy (Edited by J. C. Hilliard and G. S. Springer), 1985 (Plenum Press, New York) ch. 3.

6 Ballal, D. R. and Lefebvre, A. H. The influence of spark discharge characteristics on minimum ignition energy in flowing gases. Combust. Flame, 1975, 24, 99-108.

7 Ballal, D. R. and Lefebvre, A. H. A general model of spark ignition for gaseous and liquid fuel-air mixtures. In Proceedings of the 18th International Symposium on Combustion, Waterloo, Canada, August 1981, (The Combustion Institute, Pittsburgh, PA) pp. 321-328.

8 Merer, R. M. and Wallace, J. S. Spark spectroscopy for spark ignition engine diagnostics. SAE paper 950164, 1995.

9 Lee, M. J., Hall, M., Ezekoye, O. A., and Matthews, R. Voltage, and energy deposition characteristics of spark ignition systems. SAE paper 2005-01-0231, 2005.

10 Maly, R. and Vogel, M. Initiation and propagation of flame fronts in lean $\mathrm{CH}_{4}$-air mixtures by the three modes of the ignition spark. In Proceedings of the Seventeenth International Symposium on Combustion, Leeds, UK, August 1978, (The Combustion Institute, Pittsburgh, PA) pp. 821-831.

11 Maly, R., Meinel, H., and Wagner, E. Novel method for determining general flow parameters from conventional spark discharges. IMechE Conference Transactions C67/83, 1983, 27-32.

12 Ziegler, G. F. W., Wagner, E. P., and Maly, R. R. Ignition of lean methane-air mixtures by high pressure glow and arc discharges. In Proceedings of the 20th International Symposium on Combustion, Ann Arbor, MI, August 1984 (The Combustion Institute, Pittsburgh, PA) pp. 1817-1824.

13 Kim, J. and Anderson, R. W. Spark anemometry of bulk gas velocity at the plug gap of a firing engine. SAE paper 952459, 1995.

14 Fansler, T. D., Stojkovic, B., Drake, M. C., and Rosalik, M. E. Local fuel concentration measurements in internal combustion engine using sparkemission spectroscopy. Appl. Phys. B, 2002, 75, 577-590.

15 Ko, Y., Anderson, R. W., and Arpaci, V. S. Spark ignition of propane - air mixtures near the minimum ignition energy: part I. An experimental study. Combust. Flame, 1991, 83, 75-87.

16 Dugler, M. and Sher, E. Experimental study on spark ignition of flowing combustible mixtures. SAE paper 951004, 1995.

17 Riven, B., Dulger, M., and Sher, E. Extending lean misfire limit of methane-air mixtures by means of an enhanced spark discharge. SAE paper 1999-010573, 1999.

18 Geiger, J., Pischinger, S., Böwing, R., Koß, H.-J., and Theimann, J. Ignition systems for highly diluted mixtures in SI-engines. SAE paper 1999-01-0799, 1999.

19 Nakai, M., Nakagawa, Y., Hamai, K., and Sone, M. Stabilized combustion in a spark ignited engine 
through a long spark discharge. SAE paper 850075 , 1985.

20 Maly, R. Ignition model for spark discharges and the early phase of flame front growth. In Proceedings of the 18th International Symposium on Combustion, Waterloo, Canada, August 1981, (The Combustion Institute, Pittsburgh, PA) pp. 1747-1754.

21 Arcoumanis, C. and Bae, C.-S. Correlation between spark ignition characteristics and flame development in a constant-volume combustion chamber. SAE paper 902413, 1992.

22 Fansler, T. D., Drake, M. C., Stojkovic, B., and Rosalik, M. E. Local fuel concentration, ignition and combustion in a stratified-charge spark-ignited direct-injection engine: spectroscopic, imaging and pressure-based measurements. Int. J. Eng. Res., 2003, 4, 61-86.

23 Peterson, B. and Sick, V. Simultaneous flow field and fuel concentration imaging at $4.8 \mathrm{kHz}$ in an operating engine. Appl. Phys. B, 2009, 97, 887895.

24 Fajardo, C. M. and Sick, V. Flow field assessment in a fired spray-guided spark-ignition direct-injection engine based on UV particle image velocimetry with sub crank angle resolution. Proc. Combust. Inst., 2007, 31, 3023-3031.

25 Smith, J. D. and Sick, V. Quantitative, dynamic fuel distribution measurements in combustion-related devices using laser-induced fluorescence imaging of biacetyl in iso-octane. Proc. Combust. Inst., 2007, 31, 747-755.

26 Adrian, R. J. Dynamic ranges of velocity and spatial resolution of particle image velocimetry. Meas. Sci. Technol., 1997, 8, 1393-1398.

27 Peterson, B., Reuss, D. L., and Sick, V. High-speed imaging analysis of misfires in a spray-guided direct injection engine. Proc. Combust. Inst., accepted for publication, DOI: 10.1016/j.proci.2010.07.079 